OPEN ACCESS

Edited by:

Alessandro Russo,

University of Pisa, Italy

Reviewed by:

Kátia Regina Dos Santos,

Federal University of Rio de

Janeiro, Brazil

David Paterson,

The University of Queensland,

Australia

*Correspondence:

Mathias W. Pletz

mathias.pletz@med.uni-jena.de

Specialty section:

This article was submitted to Infectious Diseases - Surveillance,

Prevention and Treatment,

a section of the journal

Frontiers in Medicine

Received: 12 October 2020

Accepted: 31 December 2020

Published: 05 March 2021

Citation:

Kimmig A, Hagel S, Weis S, Bahrs C,

Löffler B and Pletz MW (2021)

Management of Staphylococcus aureus Bloodstream Infections.

Front. Med. 7:616524

doi: 10.3389/fmed.2020.616524

\section{Management of Staphylococcus aureus Bloodstream Infections}

\author{
Aurelia Kimmig ${ }^{1}$, Stefan Hagel ${ }^{1}$, Sebastian Weis ${ }^{1,2,3}$, Christina Bahrs ${ }^{1,4}$, Bettina Löffler ${ }^{5}$ \\ and Mathias W. Pletz ${ }^{1 *}$ \\ ${ }^{1}$ Institute for Infectious Diseases and Infection Control, Jena University Hospital, Friedrich-Schiller-University Jena, Jena, \\ Germany, ${ }^{2}$ Department of Anesthesiology and Intensive Care Medicine, Jena University Hospital, Friedrich-Schiller-University \\ Jena, Jena, Germany, ${ }^{3}$ Center for Sepsis Control and Care, Jena University Hospital, Friedrich-Schiller-University Jena, Jena, \\ Germany, ${ }^{4}$ Division of Infectious Diseases and Tropical Medicine, Department of Medicine I, Medical University of Vienna, \\ Vienna, Austria, ${ }^{5}$ Institute of Medical Microbiology, Jena University Hospital, Friedrich-Schiller-University Jena, Jena, Germany
}

Staphylococcus aureus bloodstream infections are associated with a high morbidity and mortality. Nevertheless, significance of a positive blood culture with this pathogen is often underestimated or findings are misinterpreted as contamination, which can result in inadequate diagnostic and therapeutic consequences. We here review and discuss current diagnostic and therapeutic key elements and open questions for the management of Staphylococcus aureus bloodstream infections.

Keywords: Staphylococcus aureus blood stream infections, endocarditis, diagnostic and therapeutic algorithm, current recommendations, open questions

\section{INTRODUCTION}

Staphylococcus aureus (S. aureus) is one of the leading pathogens causing community-acquired and hospital-acquired bloodstream infections ranking second after Escherichia coli. Incidences were estimated between 10 to 30 cases per 100,000 person-years (1) and hospital mortality is high, ranging between 15 and $40 \%(2,3)$.

The gram-positive pathogen has developed several strategies to adapt to the infected host by evading the hosts immune system, e.g., it can form biofilms, adhering to intravascular catheters and implantable medical devices (4). Furthermore, intracellular persistence in different kind of host cells such as epithelial and endothelial cells or osteoblasts, has been described (5). Inside these biofilms and host cells, $S$. aureus can form slow growing subpopulation, so called small colony variants (SCV). These colonies display a lower metabolic activity and have an increased tolerance against antibiotics, which can result in refractory or chronic infections and relapses $(6,7)$.

In $8-15 \%$ of the patients, hematogenous spread may also lead to later secondary complications such as endocarditis, vertebral osteomyelitis, abscesses, and implant associated infections of prosthetic joints, electronic cardiac devices etc., which can occur up to weeks or months after the primary infection. Notably, patients with community-acquired SA-BSI and patients with prolonged bacteremia have an increased risk for secondary foci (8). Further risk factors for complications are inadequate antibiotic treatment, an unknown primary focus of infection or insufficient source control (9).

Given the high rates of mortality and morbidity associated with SA-BSI the management differs from bloodstream infections with other bacteria. A structured management in diagnostic and treatment is crucial for an optimal outcome. Several studies have shown that an adherence to treatment guidelines and infectious disease bedside-consultation can lead to a reduction of mortality by up to $50 \%(10-12)$. 


\section{CURRENT DIAGNOSTIC AND TREATMENT STANDARDS}

\section{Diagnostic Key Principles}

As a principle, blood cultures positive for $S$. aureus always need to be respected as a clinically significant finding and should result in an appropriate treatment. Blood culture contamination with $S$. aureus is a very rare event $(<5 \%)$ and due to the high mortality and the high risk of serious complications associated with $S$. aureus bloodstream infections (SA-BSI), a prompt therapy is generally recommended (12-14).

$S$. aureus detection in urine culture ( $S$. aureus bacteriuria) should lead to the search of an underlying bloodstream infection as $S$. aureus rarely causes genuine urinary tract infection, but is most likely filtrated through the kidneys $(15,16)$. An exception are patients with urinary tract foreign bodies and/or after urological interventions. In these patients, the urinary tract can be the primary focus of a bloodstream infection with the pathogen. S. aureus bacteriuria in patients with a SA-BSI has been associated with a worse outcome (17). Careful patient history and thorough physical examination with a special emphasis on potential foci are mandatory. Most frequent sources of SA-BSI are intravascular catheters and soft tissue infections (18). Further diagnostics have to be performed depending on clinical findings. In up to one third of all cases, however, septic embolism remains inapparent in the clinical examination and will be diagnosed solely in an extended diagnostic work-up imaging (19).

In order to prevent further spreading of $S$. aureus causing secondary septic metastases, source control must be carried out as quickly as possible. Infected foreign bodies incl. vascular catheters or cardiac electronic devices have to be removed quickly and completely in addition to an adequate antibiotic treatment $(20,21)$. If vascular catheters have been in situ during bacteremia, a removal should be considered even if another site is suspected as focus of the SA-BSI since catheters remain the most frequent primary source of infection and moreover

Diagnostic algorithm

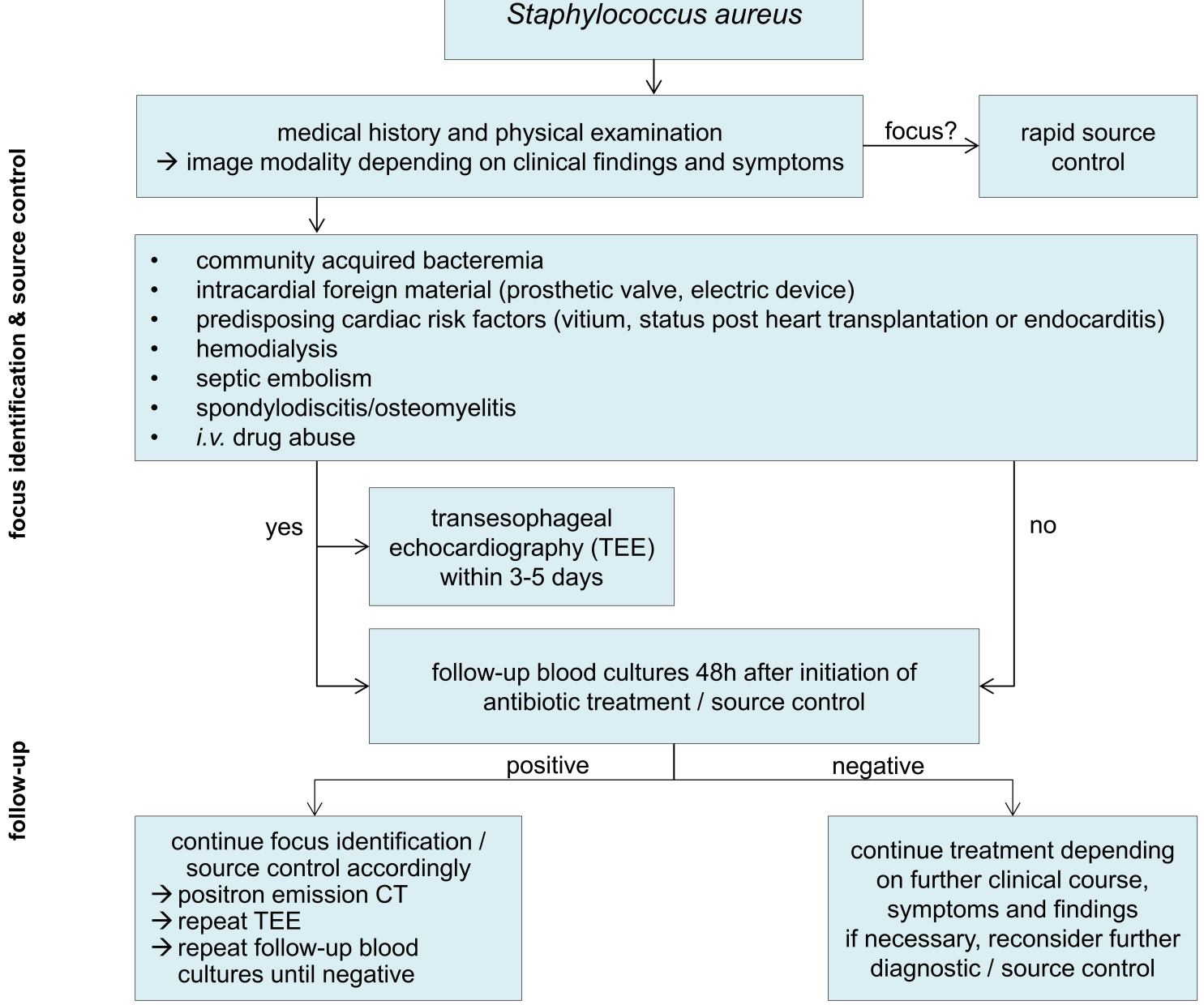

FIGURE 1 | Diagnostic algorithm. 
there is a high risk of secondary catheter colonization (22-25). Endocarditis occurs in about $10-20 \%$ of patients with SA-BSI and worsens the patient's prognosis $(26,27)$. The diagnostic sensitivity of transesophageal echocardiography (TEE) is twice as high as the one of a transthoracic echocardiography (TTE) and should thus be used preferably (28). Ideally, TEE is performed within a few days (3-5 days) after diagnosis of a SA-BSI. In patients with persisting clinical suspicion of endocarditis and/or positive follow-up blood cultures, a repeated TEE after about 7 days is recommended $(29,30)$.

Twenty-four hours (up to $72 \mathrm{~h}$ at the latest) after the initiation of therapy, follow-up blood cultures are required to evaluate therapy success (31). Positive blood cultures at this point are associated with the presence of septic metastasis, insufficient source control, and consequently with a poorer outcome and therefore require further investigation $(31,32)$. It has been recommended to take at least two blood culture pairs at each time of collection as the sensitivity of blood culture depends on the number sampled $(33,34)$. However, at least for further follow-up blood cultures and particularly in intensive care units patients, this has to be weighed with the aims of "patient blood management" (35).

In patients with positive follow-up blood cultures, a fluorodeoxyglucose positron emission computed tomography scan (FDG-PET CT) should be considered. In a cohort study on 115 patients with gram-positive bacteremia (56\% with S. aureus), PET-CT imaging had a very high sensitivity and specificity and detected twice as many septic embolisms compared to conventional diagnostic methods (19). An overview of the diagnostic key priciples is shown in Figure 1.

\section{Therapeutic Key Principles}

Antibiotics of choice in the therapy of bloodstream infections by methicillin (oxacillin) sensitive $S$. aureus (MSSA) are beta-lactam antibiotics with high activity against $S$. aureus. Best outcomes are being achieved with anti-staphylococcal penicillins (e.g., flucloxacillin) and first generation cephalosporins (cefazolin). A recent meta-analysis showed that cefazolin is not inferior to a therapy with anti-staphylococcal penicillins in the therapy of MSSA bloodstream infections (36). Moreover, cefazolin treatment was associated with a significant lower risk for drug side effects (nephrotoxicity, hepatotoxicity, venous irritation) and was associated with a numerically higher survival rate.

Piperacillin/tazobactam, ceftriaxon, cefuroxim and other broad spectrum beta-lactams should not be used for definite treatment of SA-BSI despite in vitro confirmed susceptibility, because they are not only associated with a higher likelihood to select multi-drug resistant pathogens but also with an increased mortality according to retrospective studies (37).

The relevance of penicillin allergy has recently been discussed (38). In case of an IgE-mediated (immediate type) penicillin allergy, daptomycin is recommended as an alternative to $\beta$ lactam antibiotics (39). Vancomycin application was associated with increased mortality compared to $\beta$-lactam antibiotics and therefore is not recommended for the definite treatment of MSSA bloodstream infections (40).
Antibiotics of choice for treating bloodstream infections due to methicillin (oxacillin) resistant $S$. aureus isolates (MRSA) are vancomycin and daptomycin (41). The reference range for vancomycin trough levels is $15-20 \mathrm{mg} / \mathrm{l}(12,42)$. Lower trough levels have been associated with treatment failure (43). Another reason for treatment failure and poorer outcome is a reduced vancomycin susceptibility (44-46). Vancomycin resistance is defined by a minimum inhibitory concentration (MIC) of $\geq 16 \mu \mathrm{g} / \mathrm{ml}$, strains with a MIC of $4-8 \mu \mathrm{g} / \mathrm{ml}$ are so called "vancomycin intermediate susceptible $S$. aureus" (VISA) (47). The term "hetero-resistant" VISA (hVISA) refers to $S$. aureus strains that are primarily within the susceptible range but contain subpopulations which can develop a reduced susceptibility under exposure to vancomycin (48). Patients with hVISA BSI are at higher risk of having a persistent bacteremia, which is associated with higher mortality in SA-BSI $(49,50)$. Altogether, occurrence of isolates with reduced susceptibility to vancomycin has increased over the last years probably also due to more frequent use of vancomycin in patients with MRSA infections (51). However, prevalence is still low with under 5\% and daptomycin remains an effective treatment option in these isolates $(52,53)$.

Daptomycin monotherapy (with $8-12 \quad \mathrm{mg} / \mathrm{kg}$ ideal bodyweight) is considered an equivalent alternative. Daptomycin has been shown to be inactive in patients with pneumonia, probably because it is inactivated by pulmonary surfactant and therefore unsuitable in patients with pneumogenic infection (54). Linezolid should not be used for MRSA bloodstream infection due to its bacteriostatic effect (55).

The new MRSA effective cephalosporins (ceftarolin, ceftobiprole) and lipoglycopeptides (dalbavancin) should not yet be used as first choice as there are no randomized controlled trials in patients with MRSA bloodstream infections (56-58).

Treatment duration depends on the clinical course and classification of infection as "complicated" or "uncomplicated"

BOX 1 | "Uncomplicated" Staphylococcus aureus bloodstream infection (41).

no evidence of endocarditis in the physical examination or echocardiography no implanted foreign bodies in situ (e.g., prosthetic valves, cardiac electronic device, prosthetic joints)

negative blood cultures 48-96 h after initiation of therapy

no evidence of deep-seated focus or septic metastases (e.g., vertebral osteomyelitis)

defervescence within 48-72 h after initiation of therapy

BOX 2 | Prerequisite criteria for an oral sequential therapy (59).

adequate reduction of inflammatory parameters

clinically satisfactory response to treatment

no evidence of abscess, insufficient source control or endocarditis

temperature $<38.0^{\circ} \mathrm{C} / 100.4^{\circ} \mathrm{F}$ for $>48 \mathrm{~h}$

negative follow-up blood cultures 


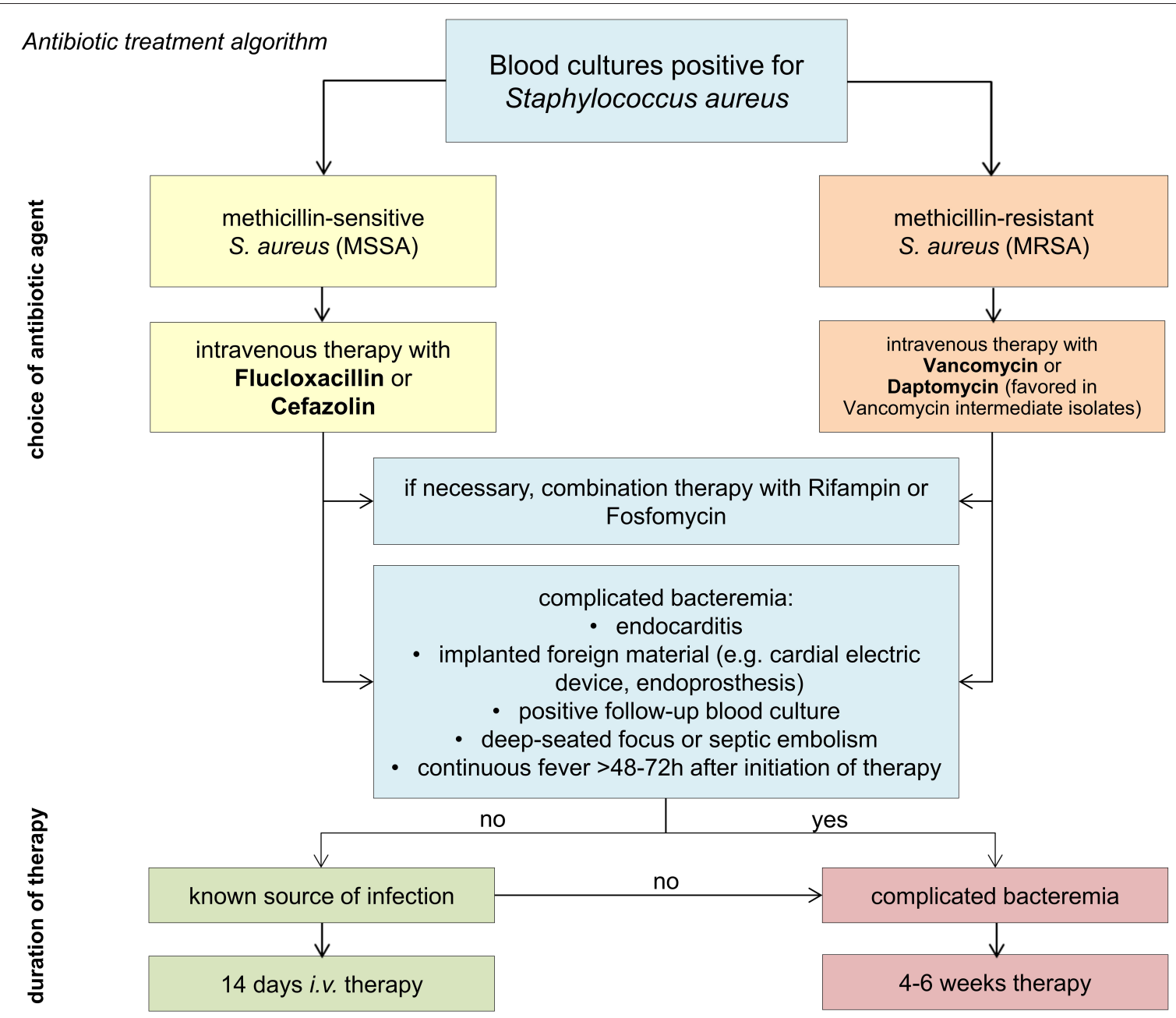

FIGURE 2 | Antibiotic treatment algorithm.

SA-BSI (Box 1). For patients with uncomplicated bloodstream infection an intravenous antibiotic treatment is recommended for at least 14 days. SA-BSI classified as complicated or without known source of infection require a minimum of 4-6 weeks of therapy. After completion of at least 14 days i.v. antibiotic therapy, an oral sequential therapy can be considered (Box 2). For an overview of the therapeutic principles (see Figure 2).

\section{Pertinent Open Questions}

Despite its frequency, the quality of evidence for the treatment of patients with SA-BSI is insufficient with only few randomized controlled trials and only a handful of larger multicenter retrospective studies available (3, 26, 60-62). The following chapter summarizes open questions and associated recent data.

\section{CURRENT QUALITY EVIDENCE AND OPEN QUESTIONS}

\section{Who Needs Echocardiography?}

Endocarditis is a dreaded complication of SA-BSI. Recently published studies show, that indication for an echocardiography should be risk-adjusted as not all patients have the same risk of acquiring an endocarditis (30, 63-65). Currently, a TEE is recommended in the following situations: community-acquired SA-BSI, prolonged bacteremia, history of intravenous drug abuse or dialysis, cardiac risk factors (foreign bodies, valve defects, history of endocarditis, heart transplant), septic embolism, e.g., vertebral osteomyelitis or cerebral embolism $(30,63,65)$. Since clinical presentation of symptoms and findings are not specific, scores may be a helpful tool to identify patients who need transesophageal echocardiography. However, so far only retrospective studies have been performed on this topic (30, 65). Moreover, a large number of risk factors for endocarditis have been described in the literature to date $(27,65,66)$ and hence, they apply to a large number of patients in daily clinical routine.

\section{How Long Do We Have to Treat?}

It is recommended to treat an uncomplicated SA-BSI for at least 14 days to avoid relapse (67). Among others, a prospective observational cohort study showed that relapse occurred in up to 8 vs. $0 \%$ of patients with short-course therapy $<14$ days (68). 
In complicated SA-BSI and episodes with unknown primary focus of infection international experts recommend at least 28 days of antibiotic therapy (67). However, underlying evidence is not satisfactory (69) and guidelines and recommended quality indicators are mainly based on retrospective data (62, 7073). Moreover, recommendations regarding treatment standards mostly refer to studies showing an improvement of outcomes by means of adherence to a bundle of measures or infectious specialist consultations (67). Randomized trials are needed to provide more evidence to what extend respective treatment elements such as duration of antibiotic therapy contribute to an improvement of patient outcomes.

\section{Can We Switch to Oral Antibiotics?}

Currently at least 14 days of parenteral antibiotic therapy are recommended in patients with a SA-BSI. At what point, or whether a switch to oral therapy is safe at all, is a matter of debate. In a recently published randomized multicenter trial by Iversen et al. changing to oral antibiotic combination treatment (e.g., dicloxacillin or linezolid plus rifampcin) was noninferior to continued intravenous treatment for patients with left side endocarditis including patients with $S$. aureus endocarditis (59). However, the outcome of the study was mainly carried by patients with native valve endocarditis due to streptococci (196 out of 400 patients). Therefore, it is unclear whether the conclusion of the study also applies to patients with $S$. aureus endocarditis. Comparable evidence for other foci of SA-BSI is lacking. Obviously, a sufficient oral bioavailability of the applied antibiotic is essential in any case. Possibly, the SABATO trial which finished recruitment recently will provide new aspects (61). The major objective of the randomized, parallel-group, observer-blinded, clinical non-inferiority trial is to demonstrate that in patients with low-risk SA-BSI a switch from intravenous to oral antimicrobial therapy is non-inferior to a conventional course of intravenous therapy.

\section{What Is the Role of Combination Therapy?}

The role of combination therapy, particularly with rifampicin or fosfomycin, in addition to a ß-lactam antibiotic, in MSSA, or vancomycin, in MRSA, SA-BSI, is a matter of debate. Theoretically, combination therapy could lead to a higher bactericidal activity compared to antibiotic monotherapy and synergistic effects could occur. Combination therapy may be superior in the eradication of intracellular staphylococci and biofilms on foreign materials and thus reduce the risk of secondary late infection and recurrence $(74,75)$.

\section{REFERENCES}

1. Laupland KB, Lyytikäinen O, Søgaard M, Kennedy KJ, Knudsen JD, Ostergaard C, et al. The changing epidemiology of Staphylococcus aureus bloodstream infection: a multinational population-based surveillance study. Clin Microbiol Infect. (2013) 19:465-71. doi: 10.1111/j.1469-0691.2012.03903.x

2. Nambiar K, Seifert H, Rieg S, Kern WV, Scarborough M, Gordon NC, et al. Survival following Staphylococcus aureus bloodstream infection: a prospective multinational cohort study assessing the impact of
However, disadvantages of combination therapy, such as drug-related side effects and interactions need to be considered in the benefit-risk assessment. Clinical studies have not shown a benefit of routine combination therapy for all patients with SA-BSI (3, 76-79). The multicenter randomized ARREST trial by Thwaites et al. (3) found no significant effect of additional rifampicin on treatment failure, disease recurrence, or death.

\section{The Role of Computerized Decision Systems and Phone Consultations}

A structured management in diagnostic and treatment is crucial for an optimal outcome. Several studies have shown that an adherence to treatment guidelines and particularly infectious disease bedside-consultation can lead to a reduction of mortality by up to $50 \%(10-12)$. Given the limited availability of infectious diseases physicians, who are usually based in larger hospitals and the standardized management outlined above, novel approaches are currently under investigation, such as computerized decision support systems and phone consultations, to improve outcome by providing respective expertise also in smaller hospitals $(80,81)$. However, it has yet to be proven whether these approaches are as effective as bedside-consultations by infectious diseases physicians.

\section{CONCLUSION}

Management of patients with SA-BSI remains challenging as mortality and complication rates are high and we still lack sufficient high-quality evidence addressing the most pertinent questions. A structured management preferably provided by an antibiotic stewardship team or infectious consultation including a standardized diagnostic work-up and therapeutic approach is prerequisite for all patients with SA-BSI to improve treatment quality and patient outcomes.

\section{AUTHOR CONTRIBUTIONS}

AK, SH, SW, CB, and MP: drafting of the manuscript. All authors: critical revision of the manuscript and additional important intellectual content.

\section{FUNDING}

This work was supported by the German Federal Ministry of Education and Research, grant number 01ZZ1803C.

place of care. J Infect. (2018) 77:516-25. doi: 10.1016/j.jinf.2018 08.015

3. Thwaites GE, Scarborough M, Szubert A, Nsutebu E, Tilley R, Greig J, et al. Adjunctive rifampicin for Staphylococcus aureus bacteraemia (ARREST): a multicentre, randomised, double-blind, placebo-controlled trial. Lancet. (2018) 391:668-78. doi: 10.1016/S0140-6736(17)32456-X

4. Garzoni C, Kelley WL. Staphylococcus aureus: new evidence for intracellular persistence. Trends Microbiol. (2009) 17:59-65. doi: 10.1016/j.tim.2008.11.005

5. Strobel M, Pförtner H, Tuchscherr L, Völker U, Schmidt F, Kramko N, et al. Post-invasion events after infection with Staphylococcus aureus are strongly 
dependent on both the host cell type and the infecting S. aureus strain. Clin Microbiol Infect. (2016) 22:799-809. doi: 10.1016/j.cmi.2016.06.020

6. Tuchscherr L, Medina E, Hussain M, Völker W, Heitmann V, Niemann S, et al. Staphylococcus aureus phenotype switching: an effective bacterial strategy to escape host immune response and establish a chronic infection. EMBO Mol Med. (2011) 3:129-41. doi: 10.1002/emmm.201000115

7. Kahl BC, Becker K, Löffler B. Clinical significance and pathogenesis of staphylococcal small colony variants in persistent infections. Clin Microbiol Rev. (2016) 29:401-27. doi: 10.1128/CMR.00069-15

8. Tande AJ, Palraj BR, Osmon DR, Berbari EF, Baddour LM, Lohse CM, et al. Clinical presentation, risk factors, and outcomes of hematogenous prosthetic joint infection in patients with Staphylococcus aureus bacteremia. Am J Med. (2016) 129:221.e11-20. doi: 10.1016/j.amjmed.2015.09.006

9. Seifert H, Wisplinghoff H, Kaasch A, Achilles K, Langhorst A, PeyerlHoffmann G, et al. Epidemiology, course and prognosis of Staphylococcus aureus bacteremia-preliminary results from the INSTINCT (INvasive STaphylococcus aureus INfection CohorT) cohort. Dtsch Med Wochenschr. (2008) 133:340-5. doi: 10.1055/s-2008-1046715

10. Vogel M, Schmitz RP, Hagel S, Pletz MW, Gagelmann N, Scherag A, et al. Infectious disease consultation for Staphylococcus aureus bacteremia - a systematic review and meta-analysis. J Infect. (2016) 72:19-28. doi: 10.1016/j.jinf.2015.09.037

11. Kimmig A, Weis S, Hagel S, Forstner C, Kesselmeier M, Pletz MW. Infektiologische Konsile bei Patienten mit Staphylococcusaureus-Bakteriämie - eine retrospektive Beobachtungsstudie am Universitätsklinikum Jena. Dtsch Med Wochenschr. (2018) 143:e2. doi: 10.1055/a-0816-9947

12. López-Cortés LE, Del Toro MD, Gálvez-Acebal J, Bereciartua-Bastarrica E, Fariñas MC, Sanz-Franco M, et al. Impact of an evidence-based bundle intervention in the quality-of-care management and outcome of Staphylococcus aureus bacteremia. Clin Infect Dis. (2013) 57:1225-33. doi: $10.1093 / \mathrm{cid} / \mathrm{cit} 499$

13. Hagel S, Kaasch AJ, Weis S, Seifert H, Pletz MW, Rieg S. Staphylococcusaureus-Blutstrominfektion - eine interdisziplinäre Herausforderung. Anasthesiol Intensivmed Notfallmed Schmerzther. (2019) 54:206-16. doi: 10.1055/a-0756-8263

14. Weinstein MP, Towns ML, Quartey SM, Mirrett S, Reimer LG, Parmigiani G, et al. The clinical significance of positive blood cultures in the 1990s: a prospective comprehensive evaluation of the microbiology, epidemiology, and outcome of bacteremia and fungemia in adults. Clin Infect Dis. (1997) 24:584-602. doi: 10.1093/clind/24.4.584

15. Lee BK, Crossley K, Gerding DN. The association between Staphylococcus aureus bacteremia and bacteriuria. Am J Med. (1978) 65:303-6. doi: 10.1016/0002-9343(78)90824-0

16. Pletz MW, Weis S, Forstner C, Wagenlehner F. Urosepsis. Med Klin Intensivmed Notfmed. (2018) 113:143-56. doi: 10.1007/s00063-018-0406-1

17. Chihara S, Popovich KJ, Weinstein RA, Hota B. Staphylococcus aureus bacteriuria as a prognosticator for outcome of Staphylococcus aureus bacteremia: a case-control study. BMC Infect Dis. (2010) 10:225. doi: 10.1186/1471-2334-10-225

18. Tong SY, Davis JS, Eichenberger E, Holland TL, Fowler VG. Staphylococcus aureus infections: epidemiology, pathophysiology, clinical manifestations, and management. Clin Microbiol Rev. (2015) 28:603-61. doi: 10.1128/CMR.00134-14

19. Vos FJ, Kullberg BJ, Sturm PD, Krabbe PF, van Dijk AP, Wanten GJ, et al. Metastatic infectious disease and clinical outcome in Staphylococcus aureus and Streptococcus species bacteremia. Medicine. (2012) 91:86-94. doi: 10.1097/MD.0b013e31824d7ed2

20. Döring $M$, Richter S, Hindricks G. The diagnosis and treatment of pacemaker-associated infection. Dtsch Ärztebl Int. (2018) 115:445-52. doi: 10.3238/arztebl.2018.0445

21. Fowler VG, Justice A, Moore C, Benjamin DK, Woods CW, Campbell S, et al. Risk factors for hematogenous complications of intravascular catheterassociated Staphylococcus aureus bacteremia. Clin Infect Dis. (2005) 40:695703. doi: $10.1086 / 427806$

22. Peacock SJ, Eddleston M, Emptage A, King A, Crook D. Positive intravenous line tip cultures as predictors of bacteraemia. J Hosp Infect. (1998) 40:35-8. doi: 10.1016/S0195-6701(98)90022-6
23. Mermel LA, Farr BM, Sherertz RJ, Raad II, O’Grady N, Harris JS, et al. Guidelines for the management of intravascular catheter-related infections. Clin Infect Dis. (2001) 32:1249-72. doi: 10.1086/320001

24. Ekkelenkamp MB, van der Bruggen T, van de Vijver DA, Wolfs TF, Bonten MJ. Bacteremic complications of intravascular catheters colonized with Staphylococcus aureus. Clin Infect Dis. (2008) 46:114-8. doi: 10.1086/524077

25. Böll B, Schalk E, Buchheidt D, Hasenkamp J, Kiehl M, Kiderlen TR, et al. Central venous catheter-related infections in hematology and oncology: 2020 updated guidelines on diagnosis, management, and prevention by the Infectious Diseases Working Party (AGIHO) of the German Society of Hematology and Medical Oncology (DGHO). Ann Hematol. (2021) 100:239-59. doi: 10.1007/s00277-020-04286-x

26. Chang F-Y, MacDonald BB, Peacock JE, Musher DM, Triplett P, Mylotte $\mathrm{JM}$, et al. A prospective multicenter study of Staphylococcus aureus bacteremia: incidence of endocarditis, risk factors for mortality, and clinical impact of methicillin resistance. Medicine. (2003) 82:322-32. doi: 10.1097/01.md.0000091185.93122.40

27. Rasmussen RV, Høst U, Arpi M, Hassager C, Johansen HK, Korup E, et al. Prevalence of infective endocarditis in patients with Staphylococcus aureus bacteraemia: the value of screening with echocardiography. J Echocardiogr. (2011) 12:414-20. doi: 10.1093/ejechocard/jer023

28. Bai AD, Steinberg M, Showler A, Burry L, Bhatia RS, Tomlinson GA, et al. Diagnostic accuracy of transthoracic echocardiography for infective endocarditis findings using transesophageal echocardiography as the reference standard: a meta-analysis. J Am Soc Echocardiogr. (2017) 30:63946.e8. doi: 10.1016/j.echo.2017.03.007

29. Habib G, Lancellotti P, Antunes MJ, Bongiorni MG, Casalta J-P, Del Zotti F, et al. 2015 ESC guidelines for the management of infective endocarditis: the task force for the management of infective endocarditis of the european society of cardiology (ESC). Endorsed by: European Association for CardioThoracic Surgery (EACTS), the European. Eur Heart J. (2015) 36:3075-128. doi: 10.1093/eurheartj/ehv319

30. Palraj BR, Baddour LM, Hess EP, Steckelberg JM, Wilson WR, Lahr BD, et al. Predicting risk of endocarditis using a clinical tool (PREDICT): scoring system to guide use of echocardiography in the management of Staphylococcus aureus bacteremia. Clin Infect Dis. (2015) 61:18-28. doi: 10.1093/cid/ civ235

31. Kuehl R, Morata L, Boeing C, Subirana I, Seifert H, Rieg S, et al. Defining persistent Staphylococcus aureus bacteraemia: secondary analysis of a prospective cohort study. Lancet Infect Dis. (2020) 20:1409-17. doi: 10.1016/S1473-3099(20)30447-3

32. Lesens O, Hansmann Y, Brannigan E, Remy V, Hopkins S, Martinot M, et al. Positive surveillance blood culture is a predictive factor for secondary metastatic infection in patients with Staphylococcus aureus bacteraemia. J Infect. (2004) 48:245-52. doi: 10.1016/j.jinf.2003.10.010

33. Miller JM, Binnicker MJ, Campbell S, Carroll KC, Chapin KC, Gilligan PH, et al. A guide to utilization of the microbiology laboratory for diagnosis of infectious diseases: 2018 update by the Infectious Diseases Society of America and the American Society for Microbiology. Clin Infect Dis. (2018) 67:e1-94. doi: $10.1093 / \mathrm{cid} / \mathrm{ciy} 381$

34. Seifert H, Abele-Horn M, Fätkenheuer G, Glück T, Jansen B, Kern WV, et al. Blutkulturdiagnostik: Sepsis, Endokarditis, Katheterinfektionen, Teil II. München: Elsevier Urban \& Fischer (2007). p. 59 -126.

35. Meybohm P, Kleinerüschkamp A, Zacharowski K. Patient blood management. In: Rossaint R, Werner C, Zwißler B, editors. Die Anästhesiologie. Berlin, Heidelberg: Springer Berlin Heidelberg (2019). p. 211-5.

36. Weis S, Kesselmeier M, Davis JS, Morris AM, Lee S, Scherag A, et al. Cefazolin versus anti-staphylococcal penicillins for the treatment of patients with Staphylococcus aureus bacteraemia. Clin Microbiol Infect. (2019) 25:818-27. doi: $10.1016 /$ j.cmi.2019.03.010

37. Paul M, Zemer-Wassercug N, Talker O, Lishtzinsky Y, Lev B, Samra Z, et al. Are all beta-lactams similarly effective in the treatment of methicillin-sensitive Staphylococcus aureus bacteraemia? Clin Microbiol Infect. (2011) 17:1581-6. doi: $10.1111 /$ j.1469-0691.2010.03425.x

38. Castells M, Khan DA, Phillips EJ. Penicillin allergy. N Engl J Med. (2019) 381:2338-51. doi: 10.1056/NEJMra1807761

39. Fowler VG, Boucher HW, Corey GR, Abrutyn E, Karchmer AW, Rupp ME, et al. Daptomycin versus standard therapy for bacteremia and endocarditis 
caused by Staphylococcus aureus. N Engl J Med. (2006) 355:653-65. doi: 10.1056/NEJMoa053783

40. Kim S-H, Kim K-H, Kim H-B, Kim N-J, Kim E-C, Oh M, et al. Outcome of vancomycin treatment in patients with methicillin-susceptible Staphylococcus aureus bacteremia. Antimicrob Agents Chemother. (2008) 52:192-7. doi: 10.1128/AAC.00700-07

41. Liu C, Bayer A, Cosgrove SE, Daum RS, Fridkin SK, Gorwitz RJ, et al. Clinical practice guidelines by the Infectious Diseases Society of America for the treatment of methicillin-resistant Staphylococcus aureus infections in adults and children. Clin Infect Dis. (2011) 52:e18-55. doi: 10.1093/cid/ciq146

42. Kullar R, Davis SL, Levine DP, Rybak MJ. Impact of vancomycin exposure on outcomes in patients with methicillin-resistant Staphylococcus aureus bacteremia: support for consensus guidelines suggested targets. Clin Infect Dis. (2011) 52:975-81. doi: 10.1093/cid/cir124

43. Forstner C, Dungl C, Tobudic S, Mitteregger D, Lagler H, Burgmann H. Predictors of clinical and microbiological treatment failure in patients with methicillin-resistant Staphylococcus aureus (MRSA) bacteraemia: a retrospective cohort study in a region with low MRSA prevalence. Clin Microbiol Infect. (2013) 19:E291-7. doi: 10.1111/1469-0691. 12169

44. Soriano A, Marco F, Martínez JA, Pisos E, Almela M, Dimova VP, et al. Influence of vancomycin minimum inhibitory concentration on the treatment of methicillin-resistant Staphylococcus aureus bacteremia. Clin Infect Dis. (2008) 46:193-200. doi: 10.1086/524667

45. van Hal SJ, Paterson DL. Systematic review and meta-analysis of the significance of heterogeneous vancomycin-intermediate Staphylococcus aureus isolates. Antimicrob Agents Chemother. (2011) 55:405-10. doi: 10.1128/AAC.01133-10

46. Howden BP, Ward PB, Charles PG, Korman TM, Fuller A, Du Cros P, et al. Treatment outcomes for serious infections caused by methicillin-resistant Staphylococcus aureus with reduced vancomycin susceptibility. Clin Infect Dis. (2004) 38:521-8. doi: 10.1086/381202

47. Tenover FC, Moellering RC. The rationale for revising the Clinical and Laboratory Standards Institute vancomycin minimal inhibitory concentration interpretive criteria for Staphylococcus aureus. Clin Infect Dis. (2007) 44:120815. doi: $10.1086 / 513203$

48. Hiramatsu K, Aritaka N, Hanaki H, Kawasaki S, Hosoda Y, Hori S, et al. Dissemination in Japanese hospitals of strains of Staphylococcus aureus heterogeneously resistant to vancomycin. Lancet. (1997) 350:1670-3. doi: 10.1016/S0140-6736(97)07324-8

49. Bae I-G, Federspiel JJ, Miró JM, Woods CW, Park L, Rybak MJ, et al. Heterogeneous vancomycin-intermediate susceptibility phenotype in bloodstream methicillin-resistant Staphylococcus aureus isolates from an international cohort of patients with infective endocarditis: prevalence, genotype, and clinical significance. J Infect Dis. (2009) 200:1355-66. doi: $10.1086 / 606027$

50. Minejima E, Mai N, Bui N, Mert M, Mack WJ, She RC, et al. Defining the breakpoint duration of Staphylococcus aureus bacteremia predictive of poor outcomes. Clin Infect Dis. (2020) 70:566-73. doi: 10.1093/cid/c iz257

51. Hiramatsu K. Vancomycin-resistant Staphylococcus aureus a new model of antibiotic resistance. Lancet Infect Dis. (2001) 1:147-55. doi: 10.1016/S1473-3099(01)00091-3

52. Shariati A, Dadashi M, Moghadam MT, van Belkum A, Yaslianifard S, Darban-Sarokhalil D. Global prevalence and distribution of vancomycin resistant, vancomycin intermediate and heterogeneously vancomycin intermediate Staphylococcus aureus clinical isolates: a systematic review and meta-analysis. Sci Rep. (2020) 10:12689. doi: 10.1038/s41598-02069058-Z

53. Moise PA, North D, Steenbergen JN, Sakoulas G. Susceptibility relationship between vancomycin and daptomycin in Staphylococcus aureus: facts and assumptions. Lancet Infect Dis. (2009) 9:617-24. doi: 10.1016/S1473-3099(09)70200-2

54. Silverman JA, Mortin LI, Vanpraagh AD, Li T, Alder J. Inhibition of daptomycin by pulmonary surfactant: in vitro modeling and clinical impact. $J$ Infect Dis. (2005) 191:2149-52. doi: 10.1086/430352
55. Prasad P, Sun J, Danner RL, Natanson C. Excess deaths associated with tigecycline after approval based on noninferiority trials. Clin Infect Dis. (2012) 54:1699-709. doi: 10.1093/cid/cis270

56. White BP, Barber KE, Stover KR. Ceftaroline for the treatment of methicillinresistant Staphylococcus aureus bacteremia. Am J Health Syst Pharm. (2017) 74:201-8. doi: 10.2146/ajhp160006

57. Bryson-Cahn C, Beieler AM, Chan JD, Harrington RD, Dhanireddy S. Dalbavancin as secondary therapy for serious Staphylococcus aureus infections in a vulnerable patient population. Open Forum Infect Dis. (2019) 6:ofz028. doi: 10.1093/ofid/ofz028

58. van Hise NW, Anderson M, McKinsey D, McKinsey J, Harting B, Belmares J, et al. The use of dalbavancin for Staphylococcus aureus bacteremia in persons who inject drugs (PWID). Open Forum Infect Dis. (2019) 6:S772. doi: $10.1093 /$ ofid/ofz360.1933

59. Iversen K, Ihlemann N, Gill SU, Madsen T, Elming H, Jensen KT, et al. Partial oral versus intravenous antibiotic treatment of endocarditis. N Engl J Med. (2019) 380:415-24. doi: 10.1056/NEJMoa 1808312

60. Chang F-Y, Peacock JE, Musher DM, Triplett P, MacDonald BB, Mylotte JM, et al. Staphylococcus aureus bacteremia: recurrence and the impact of antibiotic treatment in a prospective multicenter study. Medicine. (2003) 82:333-9. doi: 10.1097/01.md.0000091184.93122.09

61. Kaasch AJ, Fätkenheuer G, Prinz-Langenohl R, Paulus U, Hellmich M, Weiß V, et al. Early oral switch therapy in low-risk Staphylococcus aureus bloodstream infection (SABATO): study protocol for a randomized controlled trial. Trials. (2015) 16:450. doi: 10.1186/s13063-015-0973-x

62. Bai AD, Showler A, Burry L, Steinberg M, Ricciuto DR, Fernandes $\mathrm{T}$, et al. Impact of infectious disease consultation on quality of care, mortality, and length of stay in Staphylococcus aureus bacteremia: results from a large multicenter cohort study. Clin Infect Dis. (2015) 60:1451-61. doi: $10.1093 /$ cid/civ120

63. Kaasch AJ, Fowler VG, Rieg S, Peyerl-Hoffmann G, Birkholz H, Hellmich $\mathrm{M}$, et al. Use of a simple criteria set for guiding echocardiography in nosocomial Staphylococcus aureus bacteremia. Clin Infect Dis. (2011) 53:1-9. doi: $10.1093 / \mathrm{cid} / \mathrm{cir} 320$

64. Khatib R, Sharma M. Echocardiography is dispensable in uncomplicated Staphylococcus aureus bacteremia. Medicine. (2013) 92:182-8. doi: 10.1097/MD.0b013e318294a710

65. Tubiana S, Duval X, Alla F, Selton-Suty C, Tattevin P, Delahaye F, et al. The VIRSTA score, a prediction score to estimate risk of infective endocarditis and determine priority for echocardiography in patients with Staphylococcus aureus bacteremia. J Infect. (2016) 72:544-53. doi: 10.1016/j.jinf.2016.02.003

66. Salvador VB, Chapagain B, Joshi A, Brennessel DJ. Clinical risk factors for infective endocarditis in Staphylococcus aureus bacteremia. Tex Heart Inst J. (2017) 44:10-5. doi: 10.14503/THIJ-15-5359

67. Oever J ten, Jansen JL, van der Vaart TW, Schouten JA, Hulscher ME, Verbon A. Development of quality indicators for the management of Staphylococcus aureus bacteraemia. J Antimicrob Chemother. (2019) 74:334451. doi: $10.1093 / \mathrm{jac} / \mathrm{dkz} 342$

68. Chong YP, Moon SM, Bang K-M, Park HJ, Park S-Y, Kim M-N, et al. Treatment duration for uncomplicated Staphylococcus aureus bacteremia to prevent relapse: analysis of a prospective observational cohort study. Antimicrob Agents Chemother. (2013) 57:1150-6. doi: 10.1128/AAC.01021-12

69. Tong SY, Lee TC. Staphylococcus aureus bacteraemia: does duration matter? Lancet Infect Dis. (2020) 20:1353-4. doi: 10.1016/S1473-3099(20)30590-9

70. Iannini PB, Crossley K. Therapy of Staphylococcus aureus bacteremia associated with a removable focus of infection. Ann Intern Med. (1976) 84:558-60. doi: 10.7326/0003-4819-84-5-558

71. Raad II, Sabbagh MF. Optimal duration of therapy for catheter-related Staphylococcus aureus bacteremia: a study of 55 cases and review. Clin Infect Dis. (1992) 14:75-82. doi: 10.1093/clinids/14.1.75

72. Zeylemaker MM, Jaspers CA, van Kraaij MG, Visser MR, Hoepelman IM. Long-term infectious complications and their relation to treatment duration in catheter-related Staphylococcus aureus bacteremia. Eur J Clin Microbiol Infect Dis. (2001) 20:380-4. doi: 10.1007/PL00011278

73. Malanoski GJ. Staphylococcus aureus catheter-associated bacteremia. Arch Intern Med. (1995) 155:1161. doi: 10.1001/archinte.1995.00430110069007 
74. Rieg S, Kaasch AJ. Kontroversen im Management schwerer Staphylokokkeninfektionen. DMW Dtsch Med Wochenschr. (2017) 142:493-8. doi: 10.1055/s-0042-120983

75. Rieg S, Ernst A, Peyerl-Hoffmann G, Joost I, Camp J, Hellmich M, et al. Combination therapy with rifampicin or fosfomycin in patients with Staphylococcus aureus bloodstream infection at high risk for complications or relapse: results of a large prospective observational cohort. J Antimicrob Chemother. (2020) 75:2282-90. doi: 10.1093/jac/dk aa144

76. Rieg S, Joost I, Weiß V, Peyerl-Hoffmann G, Schneider C, Hellmich M, et al. Combination antimicrobial therapy in patients with Staphylococcus aureus bacteraemia-a post hoc analysis in 964 prospectively evaluated patients. Clin Microbiol Infect. (2017) 23:406.e1-e8. doi: 10.1016/j.cmi.2016. 08.026

77. Karlsen $\varnothing$, Borgen P, Bragnes B, Figved W, Grøgaard B, Rydinge J, et al. Rifampin combination therapy in staphylococcal prosthetic joint infections: a randomized controlled trial. J Orthop Surg Res. (2020) 15:365. doi: $10.21203 /$ rs.2.23809/v1

78. Cheng MP, Lawandi A, Butler-Laporte G, de l'Etoile-Morel S, Paquette K, Lee TC. Adjunctive daptomycin in the treatment of methicillin-susceptible Staphylococcus aureus bacteremia: a randomized controlled trial. Clin Infect Dis. (2020). doi: 10.1093/cid/ciaa1000. [Epub ahead of print].

79. Tong SY, Lye DC, Yahav D, Sud A, Robinson JO, Nelson J, et al. Effect of vancomycin or daptomycin with vs without an antistaphylococcal $\beta$ lactam on mortality, bacteremia, relapse, or treatment failure in patients with
MRSA bacteremia: a randomized clinical trial. JAMA. (2020) 323:527-37. doi: 10.1001/jama.2020.0103

80. Hagel S, Gantner J, Spreckelsen C, Fischer C, Ammon D, Saleh K, et al. Hospital-wide ELectronic medical record evaluated computerised decision support system to improve outcomes of patients with staphylococcal bloodstream infection (HELP): study protocol for a multicentre stepped-wedge cluster randomised trial. BMJ Open. (2020) 10:e033391. doi: 10.1136/bmjopen-2019-033391

81. Weis S, Hagel S, Schmitz RP, Scherag A, Brunkhorst FM, Forstner C, et al. Study on the utility of a statewide counselling programme for improving mortality outcomes of patients with Staphylococcus aureus bacteraemia in Thuringia (SUPPORT): a study protocol of a cluster-randomised crossover trial. BMJ Open. (2017) 7:e013976. doi: 10.1136/bmjopen-2016-013976

Conflict of Interest: The authors declare that the research was conducted in the absence of any commercial or financial relationships that could be construed as a potential conflict of interest.

Copyright (c) 2021 Kimmig, Hagel, Weis, Bahrs, Löfler and Pletz. This is an openaccess article distributed under the terms of the Creative Commons Attribution License (CC BY). The use, distribution or reproduction in other forums is permitted, provided the original author(s) and the copyright owner(s) are credited and that the original publication in this journal is cited, in accordance with accepted academic practice. No use, distribution or reproduction is permitted which does not comply with these terms. 